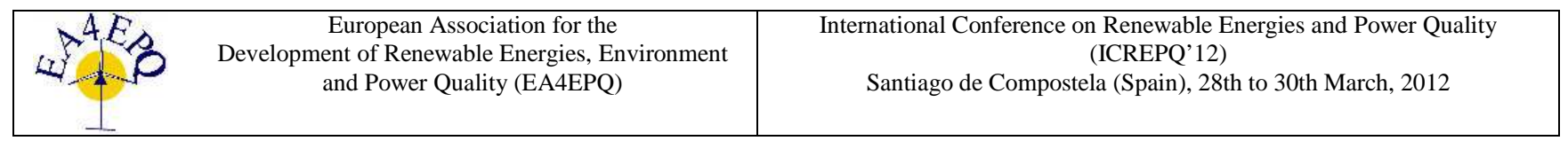

\title{
Voltage Forecasting in a Very Short Time Through the Application of Nebulous Systems
}

\author{
E. D. Garcia ${ }^{1}$, L. N. Canha ${ }^{2}$ A. R. Abaide $^{2}$, P. R. Pereira ${ }^{3}$ and R. G. Milbradt ${ }^{3}$ \\ ${ }^{1}$ Electrical Engineer of CERTAJA ENERGIA \\ Taquari, RS, Brasil \\ Master's Degree in Electrical Engineering in UFSM \\ Phone/Fax number: +55 513653 6600, e-mail: enoquedg@gmail.com \\ ${ }^{2}$ Luciane N. Canha, Alzenira R. Abaide, \\ Associate Professor, Graduate Program in Electrical Engineering - PPGEE, Center for Energy and Environment - CEEMA, \\ Federal University of Santa Maria - UFSM \\ Santa Maria, RS, Brasil \\ lncanha@ct.ufsm.br , alzenira@ct.ufsm.br \\ ${ }^{3}$ Paulo R. P. Silva, Rafael G Milbradt \\ Doctoral Student in Electrical Engineering in UFSM \\ ricardopereira.ee@ibest.com.br, rmilbradt@gmail.com
}

\begin{abstract}
It is being discussed in the global energy sector the introduction of new technologies and regulatory changes in the distribution systems of electric power, in this sense the present work aims to present a methodology for analysis and optimization of the voltage levels, from the recurrence of preview techniques applied to the setting of Smarts Grids. The results obtained in the simulations we can say that the advent of Smarts Grids enables the exploration of artificial intelligence techniques to predict voltage. The proposed methodology has resulted in the indication of the need to proactively intervene in the operation of voltage control equipment.
\end{abstract}

\section{Key words}

Voltage forecast; Smart Grid; Fuzzy and Neuro-Fuzzy; Distribution Networks; Quality Energy.

\section{Introduction}

\section{A. Smarts Grids}

The electric system configuration allows the Smarts to Grids to relate cogeneration, distributed generation, micro generation, storage, substations, devices of distribution networks, distribution, smart meters, appliances and users, illustrated in figure 1. In this sense, the proposal consistency for international standards such as IEC 61850 and IEC 61499, as well as the technological advances of quantities register devices, provide optimism of the researchers about the progress of Smarts Grids [1] [2].

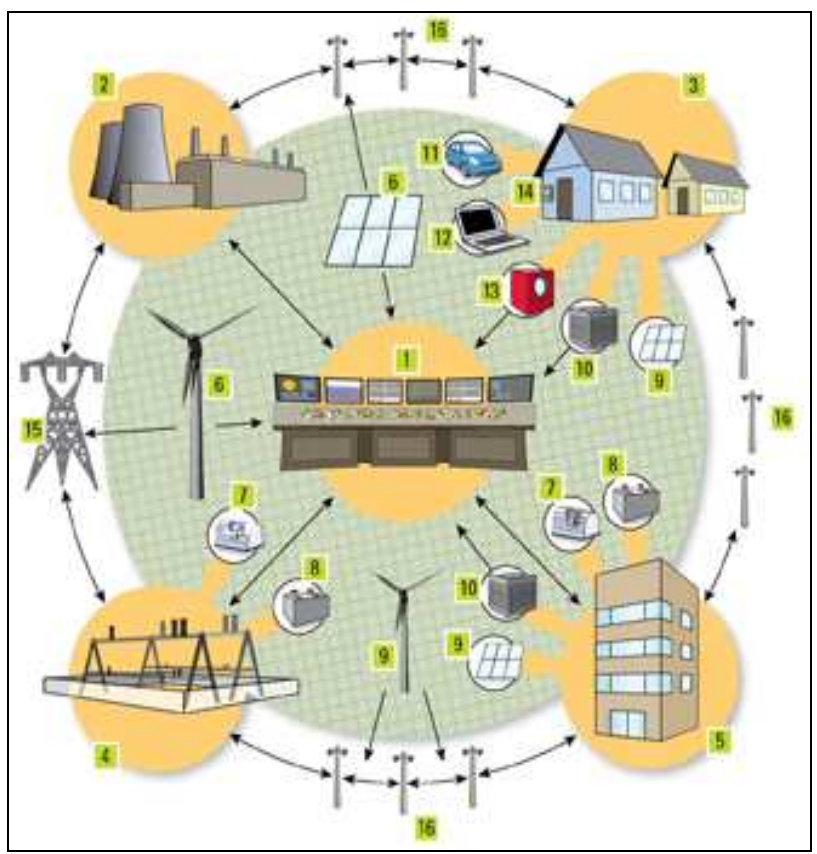

1) Centre Operation.

2) Large plants.

3) Residential consumers.

4) Substations.

5) Consumer commercial, industrial and public.

6) Small renewable generation.

7) Traditional renewable generation. 
8) Distributed storage of energy.

9) Distributed renewable generation.

10) Energy efficient equipment.

11) Electric vehicle.

12) Consumption in real time.

13) Demand management.

14) Smarts meters.

15) Transmission lines.

16) Distribution networks.

Fig. 1. Representation of the Smart Grid

Nowadays, further of Ministry of Science, technology and innovation (MCTI) and Ministry of Mine and Energy (MME) several Brazilians stakeholders are involved in researches related to the Smart Grids, however it's notable the investments in $\mathrm{P} \& \mathrm{D}$, related with the subject, such as meaning -full advances in the regular ambit as the alternation of tariff structure and the definitions of the parameters minimum contained in the smarts meters [3].

\section{B. Power Quality}

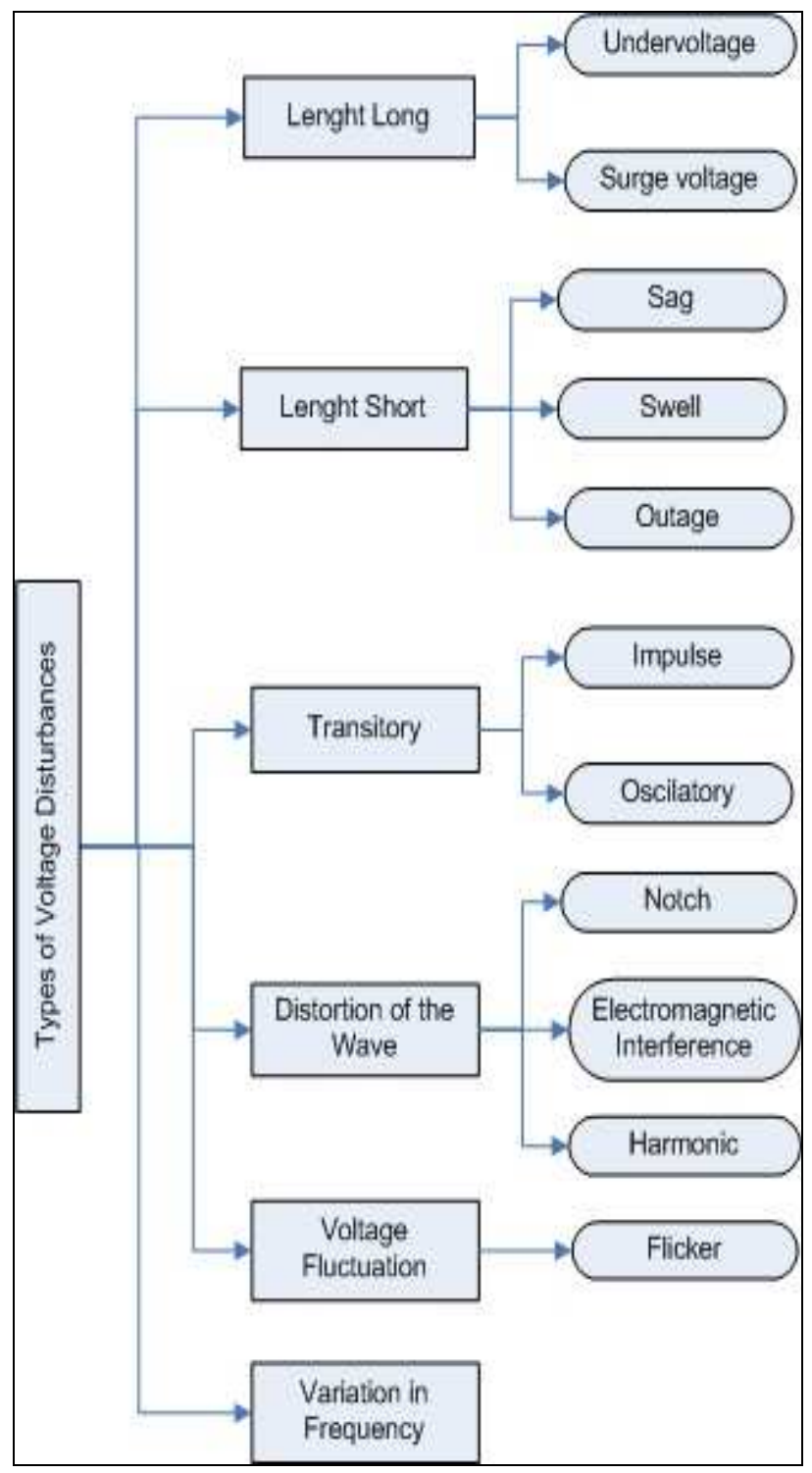

Fig. 2. Disturbances related to Electric Power
Before the big include of Smarts Grids, in this work the effort are directed to the evaluating of quality of the electric power. Meanwhile quality is also abroad concept according to the standards [4] [5] [6], since it includes items as the voltage in steady, the voltage imbalance, the voltage fluctuation, voltage variation of short duration, the sags and elevation momentary of voltage, the variety of frequency, the power factor, the voltage interruption and the harmonics, shown in figure 2. Nowadays there are plenty of studies on load preview, however another fundamental parameter for the planning and operation of the electrical system, but less explored, is the voltage stability.

Us paper [1] [8] [9] [10] e [11] reviewed the technical literature about quality of energy and developed works directed for proactive actions aimed at voltage control considering the evolution of the Smarts Grids. The stability of voltage is a relevant question, in another words, the connection of generation distributed the distribution networks. Therefore these peculiarities addition highly seasonal loads along of the year and the variations of time along of the day, became opportune news researches by the innovative methods to the proactive control of voltage, in another words, complementary alternative to power flow calculations traditional.

In Brazil, currently the quality parameters are regulated by ANEEL, whose main reference is the Module 8 of the Prodist, which specifies the allowable limits and establishes guidelines for the services and the product quality [6].

\section{The electrical system in the scenario of Smarts Grids}

Brazil has a large territory, which is an extensive feature to the transmission lines and distribution networks, consisting of circuits equally long. The Brazilian electric system is distinguished by the quantity of radial feeder circuits, before this configuration, there are a huge energy potential unexplored due to renewable sources (wind, hydro, photovoltaics, storage) are distributed along of the feeders.

Traditionally, distribution feeders originate in substations demeaning bar, at which point are the main electrical parameters monitored. In the new scenario should be monitored "TAP Zones" from the main bus, because the downstream sections are influenced by the voltage adjusting bar [12].

The implantation of automation in the distribution networks, first pass by evaluation installed equipment in the conventional networks, which shows potential to become monitoring point in the setting of Smarts Grids. Table I illustrates the progress expected in the new scenario. [2].

The installation of new control points of voltage is evaluated by calculation of power flow and the location is defined according to the configuration of the electrical system [2] [12]. 
Table I. - Comparison of Actual and Future Electric System

\begin{tabular}{|l|l|}
\hline \multicolumn{1}{|c|}{ ACTUAL } & \multicolumn{1}{|c|}{ FUTURE } \\
\hline Radial Passive System & $\begin{array}{l}\text { Integrated Distributed } \\
\text { Generation }\end{array}$ \\
\hline $\begin{array}{l}\text { Unidirectional Power Flow } \\
\text { Static }\end{array}$ & $\begin{array}{l}\text { Dynamic Bidirectional } \\
\text { Energy Flow }\end{array}$ \\
\hline Open-Loop Operation & Closed Loop Operation \\
\hline $\begin{array}{l}\text { Simple is not Directional } \\
\text { Protection }\end{array}$ & $\begin{array}{l}\text { Adaptive Directional } \\
\text { Protection }\end{array}$ \\
\hline $\begin{array}{l}\text { Simple Automation or } \\
\text { Away }\end{array}$ & $\begin{array}{l}\text { High } \\
\text { Automation }\end{array}$ \\
\hline $\begin{array}{l}\text { Simple communication or } \\
\text { Away }\end{array}$ & $\begin{array}{l}\text { Bidirectional } \\
\text { Communication }\end{array}$ \\
\hline
\end{tabular}

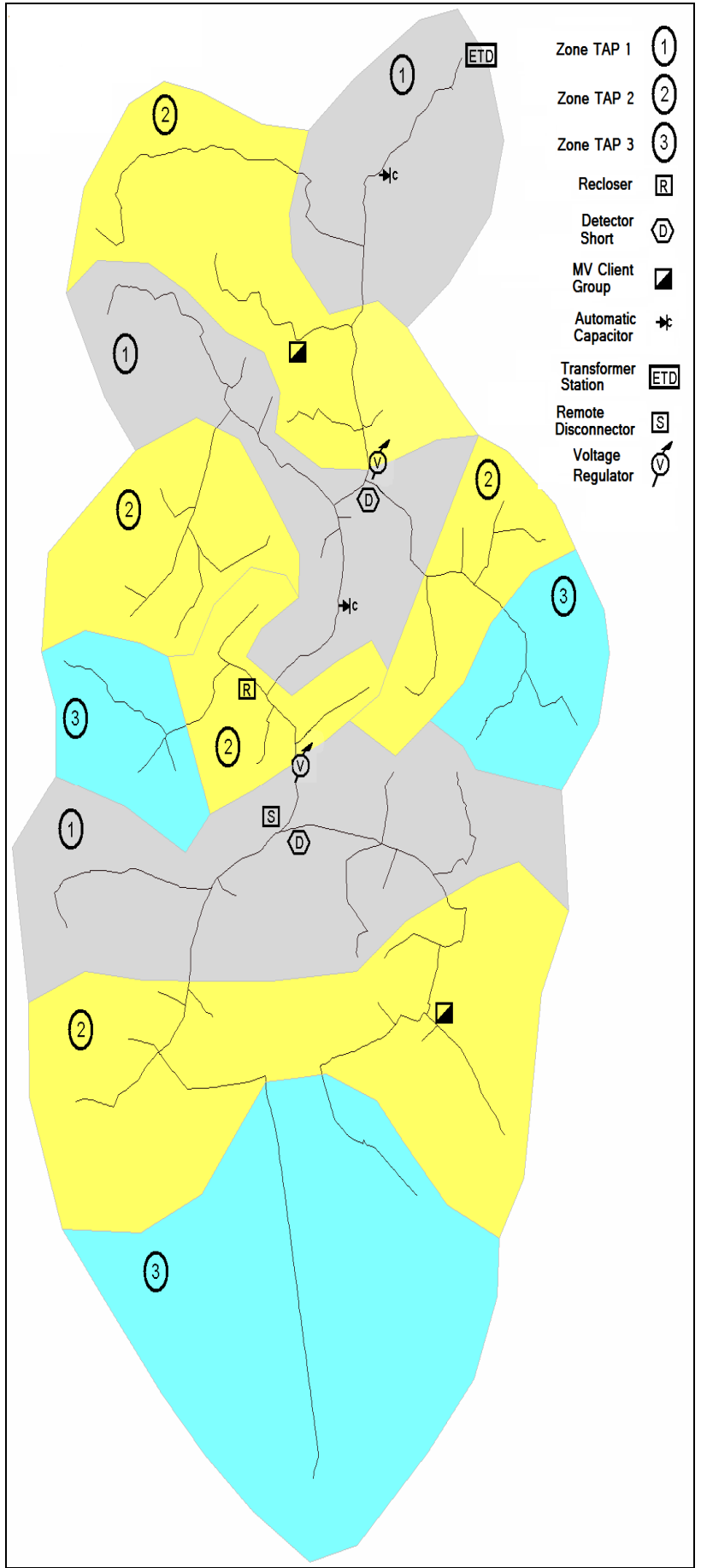

Beyond average voltage equipments with telemetry potential like voltage regulators, automatic reclosers, automated key isolators, automatic capacitor bank, remote control flags, so the advent of the Smarts Grids extend the automation another points as consumers unit of Group A, the BT concentrators and the smarts meters low voltage [7] [12].

\section{The proposed methodology}

\section{A. Fundamentals of the methodology}

In this sense, the present work propose a methodology to control of voltage in setting of the Smarts Grids from the application intelligence computational resources, in this case, use historical data and online information to predict the voltage for the following minutes.

Other important stage is the definition which electrical and metrological quantities which will be registered, as well as which mining methods of data that are applicable to treatment of information [11]. This process generates a huge volume of information, requiring application of mining techniques and statistical methods in order to provide new subsidies to data processing. Therefore it emphasizes the importance of new tools for organizing and clustering of data, especially for found nonlinear features, found in these records [13].

The figure 4 show example of originals data related to the electric current registered in a monitoring point of distribution system.

\begin{tabular}{|lllllll|}
\hline \multicolumn{9}{l}{ CTSE01SD RLAL14-Ia } & 001418 & \multicolumn{2}{l|}{ CTSE01SD RLAL1 } \\
& $23 / 06 / 2011$ & 22/06/2011 & \multicolumn{2}{l}{ 21/06/2011 } \\
$00: 00$ & A & A & A & A & A & A \\
$00: 01$ & 37,39 & 31,19 & 30,09 & 34,59 & 34,39 & 34,19 \\
$00: 02$ & 37,39 & 31,19 & 30,09 & 34,59 & 34,39 & 34,19 \\
$00: 03$ & 35,89 & 31,19 & 30,09 & 34,59 & 34,39 & 34,19 \\
\hline
\end{tabular}

Fig. 4. Example of current records

The figure 5 show the data related to the weather station close to monitoring point chosen to the study of case.

\begin{tabular}{|l|}
$A 813,01 / 07 / 2011,00,12.1,12.7,12.1,86,86,81$ \\
$, 9.8,9.9,9.5,1003.8,1004.4,1003.8,3.2,161,4.8,-3.53,0.0$ \\
A $813,01 / 07 / 2011,01,12.5,12.5,11.9,78,87,78$ \\
$8.8,9.8,8.8,1005.1,1005.1,1003.8,1.2,185,4.8,-2.80,0.0$ \\
A813,01/07/2011,02,11.6,12.6,11.6,87,89,77 \\
$9.6,10.0,8.7,1004.5,1005.3,1004.5,0.6,203,3.3,-2.37,0.0$ \\
A813,01/07/2011,03,11.3,11.6,11.3,90,90,86 \\
$9.8,9.9,9.3,1005.0,1005.0,1004.4,0.0,36,2.1,-3.32,0.0$
\end{tabular}

Fig. 5. Example of records metrological

In the figure 6 is showed an example of standardized and organized to the simulation stage, in this case, the data of monitored elements are: minute, hour, temperature, electric current, voltage, reactive power, active power and output voltage.

Fig. 3. Zones TAP a feeder 


\begin{tabular}{|lllll|}
\hline 0.966101695 & 0.608695652 & 0.857142857 & 0.371 \\
0.983050847 & 0.608695652 & 0.857142857 & 0.358 \\
1 & 0.608695652 & 0.857142857 & 0.358781058 \\
0 & 0.652173913 & 0.976833977 & 0.358781058 \\
0.016949153 & 0.652173913 & 0.976833977 & 0.358 \\
0.033898305 & 0.652173913 & 0.976833977 & 0.358 \\
0.050847458 & 0.652173913 & 0.976833977 & 0.389
\end{tabular}

Fig. 6. Example of standardized data records for simulation

From the available historical in the distributors is possible to look for news applications, in this sense, to propose the creation of setting by the excerpts feeders, considering the monitoring points available and the zones of TAP. For each one of these excerpts can be performed simulations in order to indentify the points of circuits with tendency of future violations of voltage and probably violation of quality indicators [12] [7].

In the technical literature are found several applicable techniques to forecast, or by classic methods (heuristic, statistics) or unconventional methods based on artificial intelligence (expert systems, neural networks, fuzzy models) [11]. Although some studies deal the voltage prediction, the most of studies related to the prevision are directed to load prevision in short, medium and long term [14].

Given this evidence of changes on the electric sector, the proposed methodology consist on the application of fuzzy system, such as Neuro-Fuzzy system, as long as it appropriates the use of model that combines the technology on RNA to Fuzzy Logic, therefore, it consolidates a support model to the identification trend and decision making, illustrated in figure 7 [15].

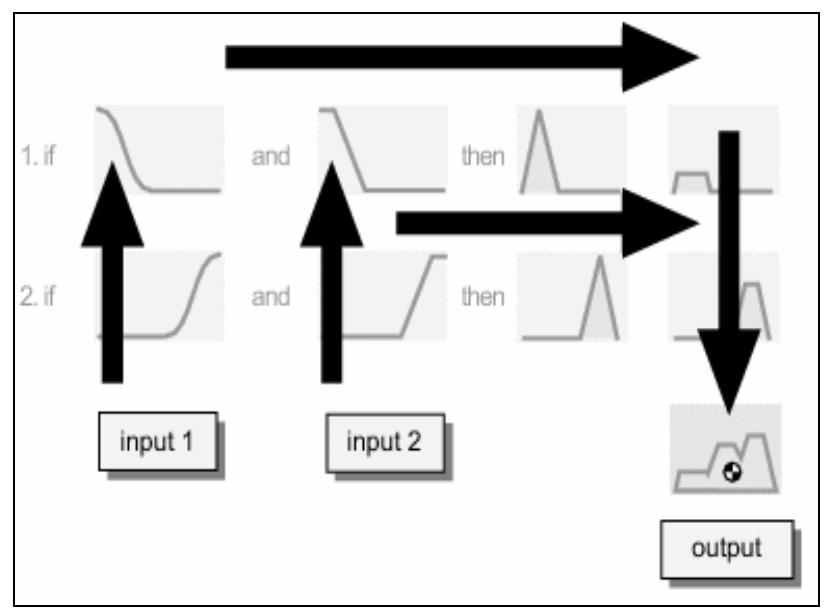

Fig. 7. Diagram of a Fuzzy Logic System

This methodology is efficient to the work with classified information as uncertain, inaccurate, diffuse, fuzzy, however is apply in the situations which the mathematics representations of problem is complex so with it is possible to fulfill the mapping nonlinear of set of data input and output [14]. Another important feature of NeuroFuzzy is the entry of quantitative and qualitative data, parameters that in this application are explored through Matlab® [13].
From the transgression simulation and violation of voltage indicators are shown for voltage control actions, whether in the control of bus voltage, operation of voltage regulators, reactive compensation, transformers with commutator of TAP with load or any other alternative actions, such as relief of the load from the signal tariff to the user.

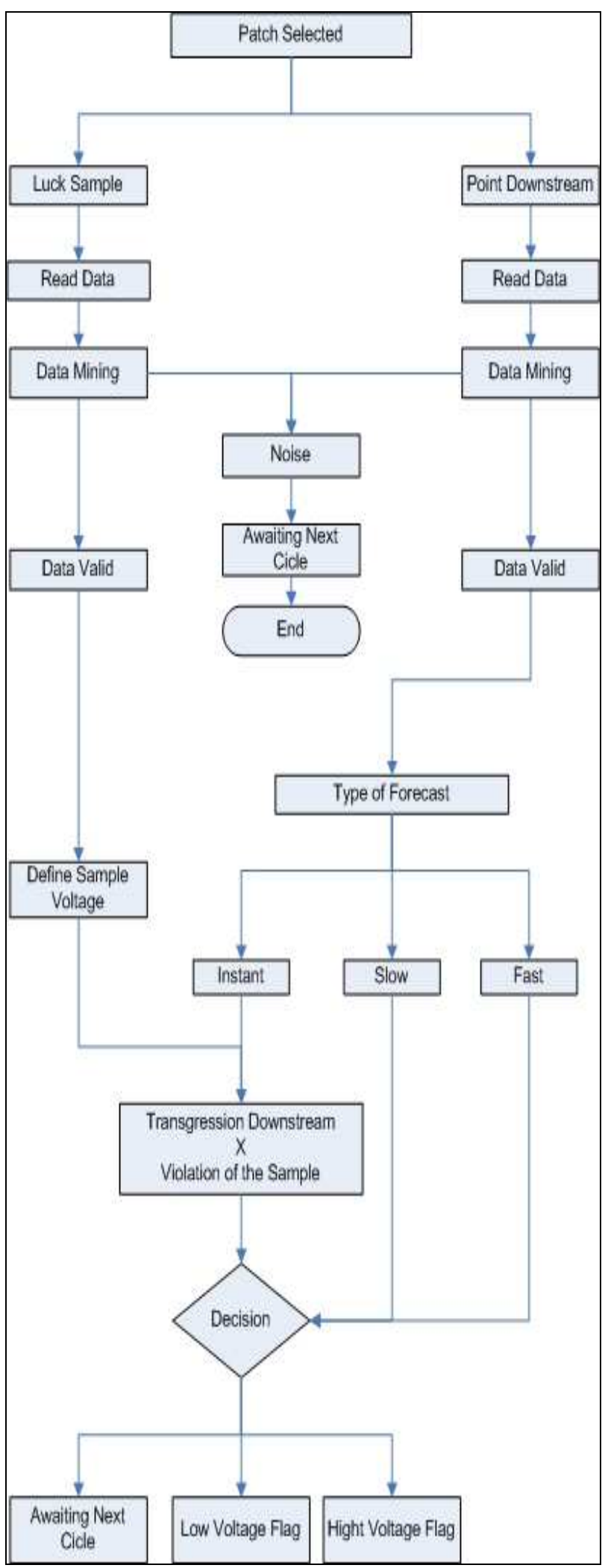

Fig. 8. Flowchart of the proposed methodology 
In the evaluation of methodology propose, illustrated in figure 8 are used as base the collected data from the supervisory system. In this case there has been used recorded data in a recloser, which is installed in an intermediate point of a feeder circuit of a distributor of electric energy. The equipment referenced has telemetry through of SCADA system (Supervisory Control And Data Acquisition) which integrates computational resources and communication channels dedicated to management of equipments of substation and distribution networks.

During the preliminary tests adopted values obtained from to measurements in substations however the voltages in this point were stable due to bar control. So, after was used the register performed in an recloser, since this equipment is installed in a distant point of demeaning substation and show a variation of voltage sufficient to rate the performance of the proposed method.

\section{B. Forecast for Neuro-Fuzzy (ANFIS)}

For the experiments were collected records of a few months, but these data were adjusted in two destined sets of training steps (training) and testing (testing and checking), as proposed in the technical literature on applications of Artificial Intelligence [13]. These mentioned data have records at intervals of one minute, with information about the current per phase, voltage between phases, active and reactive load. Complementary distribution of the data, were also obtained temperature data from historical records of a meteorological station located in the same geographic region of the distributor. Figure 9 shows the structure adopted for the prediction of voltage in a very short time.

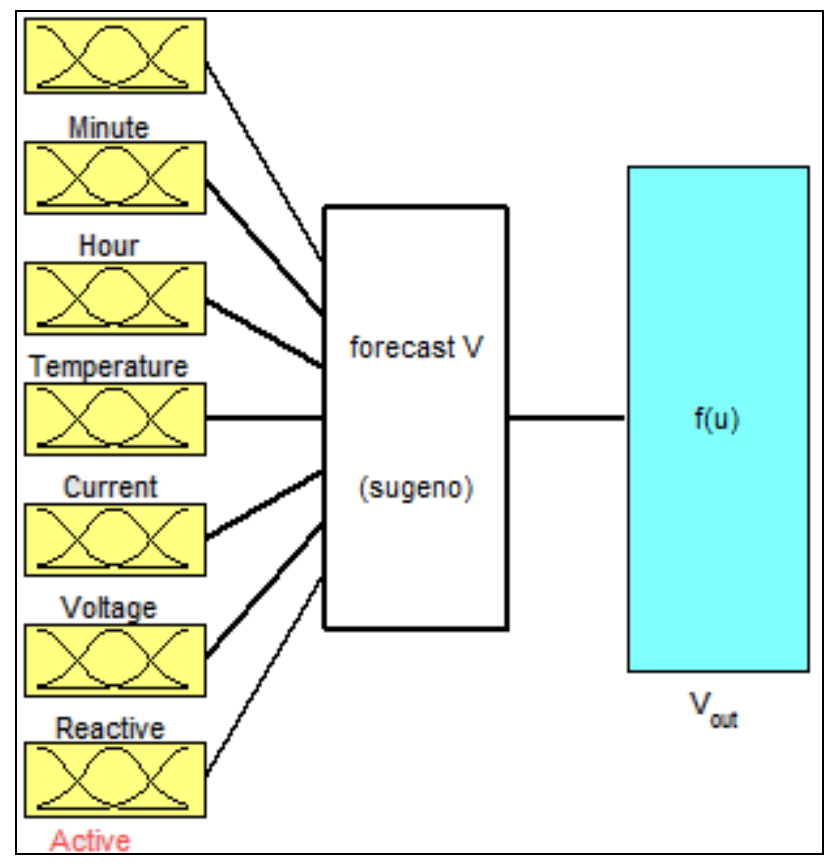

Fig. 9. Prediction model developed in ANFIS

In this work the choice of the technique "Grid partition" is related to the importance of the proposed system contemplate output variables zero. Since the choice of hybrid optimization method of training is due to its higher operating efficiency when compared to the "backpropagation" [13]. Figure 10 shows the results of ANFIS.

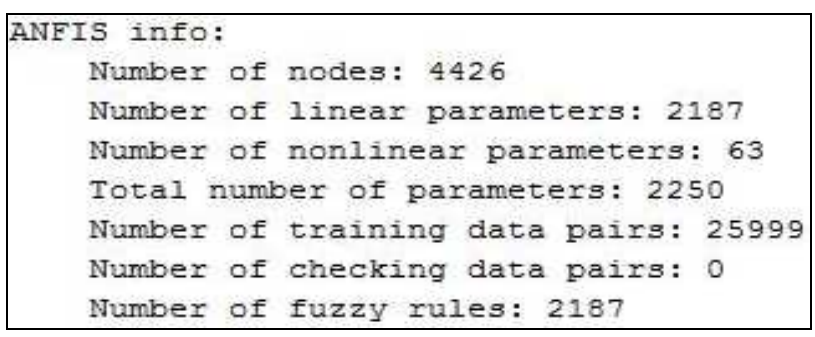

Fig. 10. Information about the simulation ANFIS

In this simulation there have been used ten times before completion of the training stage, this choice is related to the evolution of the error in relation to number of times. As a result there has been obtained 2187 rules created by ANFIS, illustrated in figure 11, and an average error less than 0,005 .

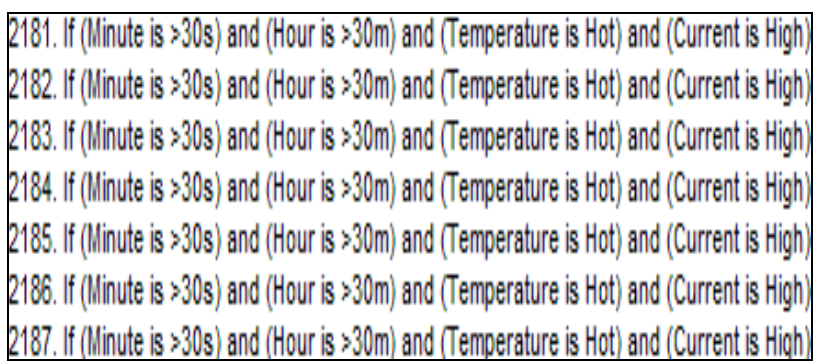

Fig. 11. Example of rules created by ANFIS

An example of the application, the Figure 12 below shows the obtained result for voltage forecast of a sequence of registers of the recloser equipment used in the study. In this situation it has obtained a good performance, it means, a low value of the average error. (Average testing erro: 0,0018272).

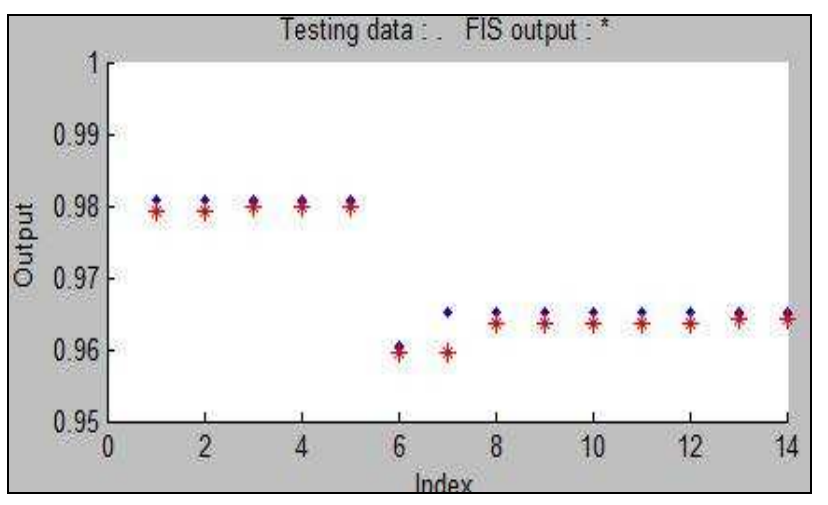

Fig. 12. Presentation of results of a predictive test

\section{Indicators through the Fuzzy Logic}

The studies of the indicators are in progress, but the proposal is to check a representative sample of consumer units in the analysis section. These data are obtained through a random drawing of monitored equipment of voltage at points of low voltage, which reading feeds a 
system of decision making based on Fuzzy Logic [13]. Differently from the previous step, developed in application to Sugeno, Neuro-Fuzzy, at this stage the FIS system adopted is the type Mandami (we command) and the rules are entered directly by a specialist [14]. Figures 13 and 14 have the diagram of the proposed rules and the proposed system for the indicator sample.

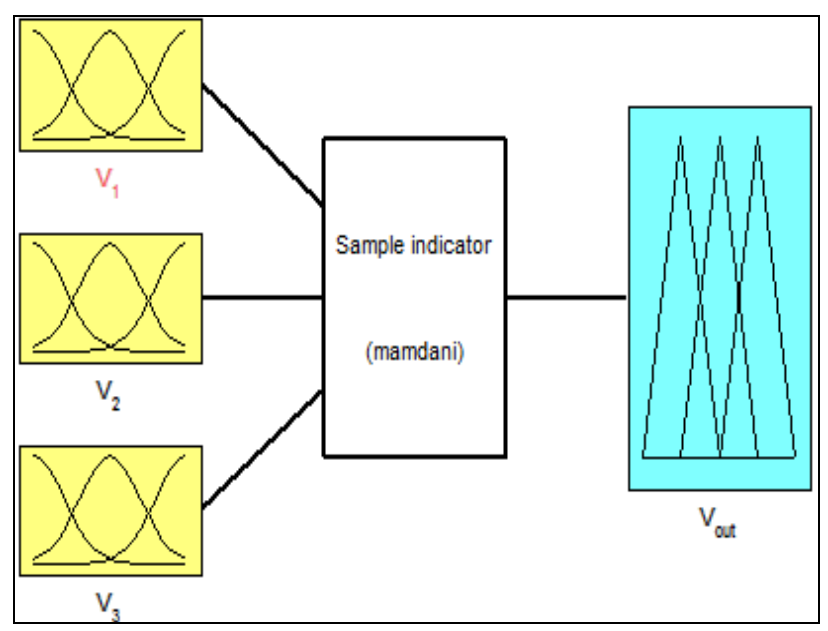

Fig. 13. Fuzzy indicator for sample

1. If $\left(V_{-} 1\right.$ is Low) and ( $V_{-} 2$ is Low) and $\left(V_{-} 3\right.$ is Low) then (V_o_U_t is Low) (1) 2. If $\left(V_{-} 1\right.$ is Normal) and $\left(V_{-} 2\right.$ is Normal) and ( $V_{-} 3$ is Normal) then ( $V_{-} O_{-} U_{-} t$ is Norm 3. If $\left(V_{-} 1\right.$ is High) and $\left(V_{-} 2\right.$ is High) and $\left(V_{-} 3\right.$ is High) then $\left(V_{-} O_{-} U_{-} t\right.$ is High) (1) 4. If $\left(V_{-} 1\right.$ is Low) and $\left(V_{-} 2\right.$ is Low) and $\left(V_{-} 3\right.$ is Normal) then ( $V_{-} O_{-} U_{-}$is Low) (1) 5. If $\left(V_{-} 1\right.$ is Normal) and (V_2 is Low) and (V_3 is Low) then (V_O_u_t is Low) (1) 6. If $\left(V_{-} 1\right.$ is Low) and (V_2 is Normal) and (V_3 is Low) then (V_O_U_t is Low) (1) 7. If $\left(V_{-} 1\right.$ is Normal) and (V_2 is Normal) and (V_3 is Low) then (V_O_U_t is Normal)

Fig. 14. Example rules indicator sampling

\section{Decision making based on Fuzzy}

The final decision is taken based on the analysis of the transgression provided for the control point of the passage and the trend of transgression identified in the sample.

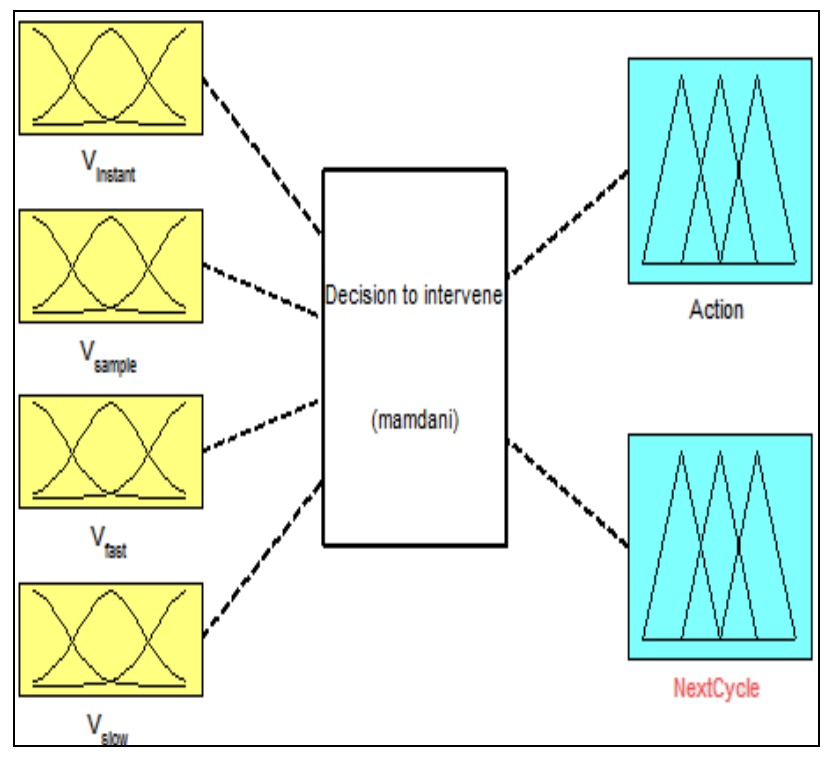

Fig. 15. Fuzzy decision to intervene
1. If (V_in_s_t_a_n t is Low) and (V_s_a_m_p__e is Low) and (V_fa_s_t is Low) 2. If (V__n_s_t_a_n_t is Normal) and (V_s_a_m_P___e is Normal) and (V___a_s_t is N 3. If (V___n_s_ta_n_t is High) and (V_s_a_m_P__e is High) and (V___a_s_t is High) 4. If (V__n_s_t_a_n_tis Low) and (V_s_a_m_p_Le is Low) and (V_fa_s_t is Low)

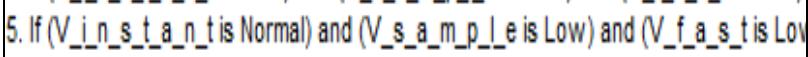

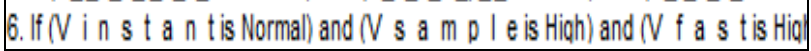

Fig. 16. Example of rules for decision to intervene

Through the tool "Signal Builder" samples the voltage of the stretch in question constitutes the set of data for the decision making on the trend of transgressing strain. For the simulations there have been used the features of Simulink ${ }^{\circledR}$, which result displayed in the output indicates the action to be taken to control the voltage.

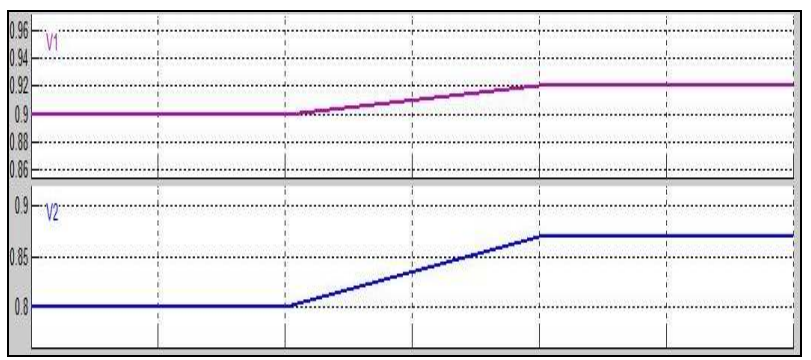

Fig. 17. Illustration of the voltage in the Signal Builder

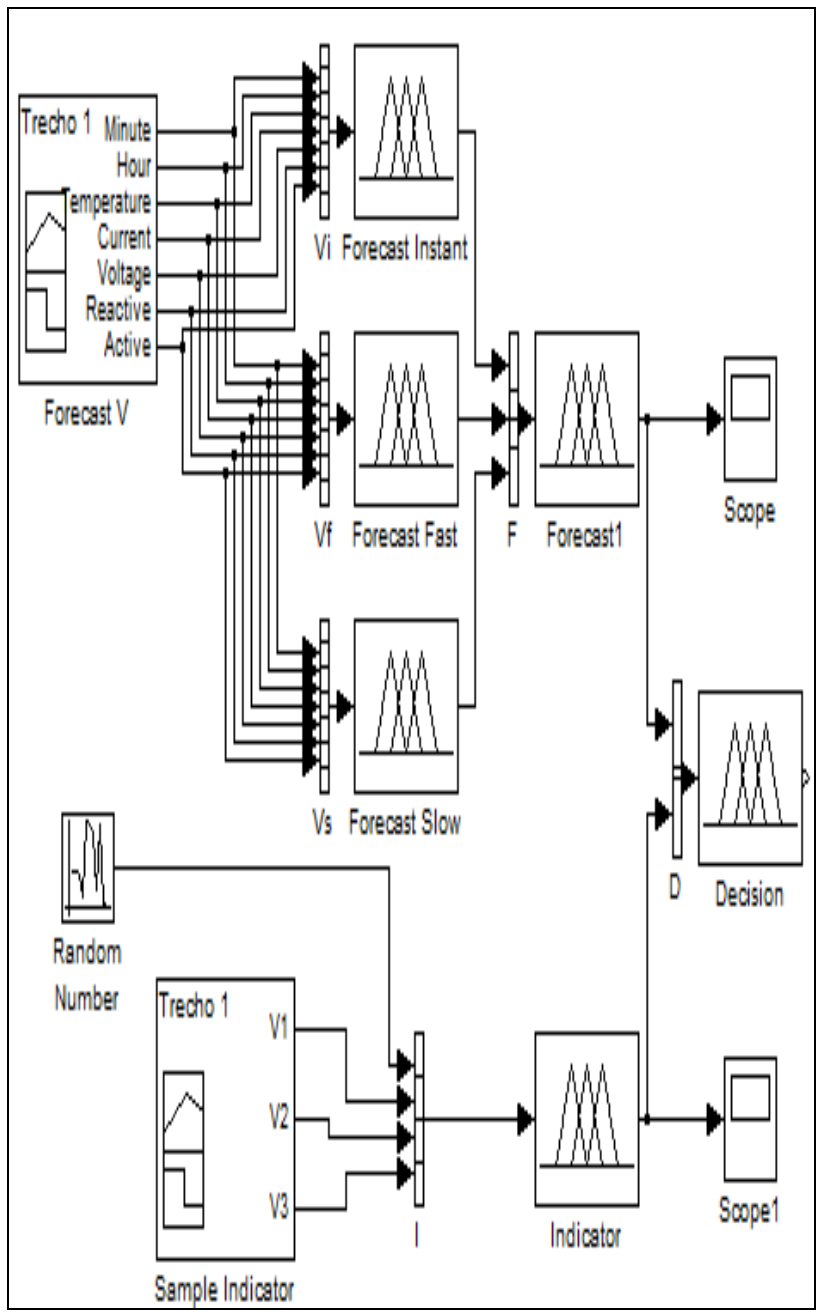

Fig. 18. Diagram developed in Simulink 


\section{Conclusion}

Given the scenario of Smarts Grids it is identified the opportunity to intensify the use of Artificial Intelligence in electrical distribution systems, such as the combination of Fuzzy Logic and Neuro-Fuzzy, explored in this work. The application of this methodology is related to proactive actions integrated into distribution networks equipped with intelligence. The control of voltage, in this scenario of Smarts Grids, besides providing care to the indices of quality, it provides increasing in the efficiency in asset utilization and therefore enable better application of resources and postponing investments. Other advantages provided in the quality of energy is the reduction of consumer complaints, reduced operating cost of inspections in the field, preventing damage to electrical equipment and alteration of the measurement campaigns. It is concluded that the advent of Smarts Grids enables the exploration of forecasting techniques for new applications, an important factor to maintain voltage stability after the connection of distributed generation.

\section{References}

[1] YE HUANG. et al. Community-Aware Scheduling Protocol for Grids. 24th AINA2010, pp. 334-341.

[2] NORTHCOTE-GREEN, James; WILSON, Robert G. Control and Automation of Electrical Power Distribution Systems. CRC Press, Boca Raton (2007), pp. 1-464.

[3] ANEEL, ANEEL Report 2010. Brasília (2011). pp. 74-83.

[4] IEC, IEC 61000: Electromagnetic Compatibility. 2005.

[5] IEEE. Std 1159: Recommended practice for monitoring electric power quality. New York: IEEE. 2009.

[6] ANEEL. Procedures for Distribution of Electrical Energy in the National Electrical System - PRODIST; Module 8 - Power Quality. Brasilia (2011), pp 1-61.

[7] MCBEE, Kerry D.; SIMOES, Marcelo G. Benefits of utilizing a Smart Grid monitoring system to improve feeder voltage. NAPS(2009), pp 1-5.

[8] FU, Le; PAL, Bikash and CORY, Brian. Voltage regulation for primary level power networks by virtual voltage coordinated control. Power Engineering Society General Meeting (2006), pp 1-6

[9] FARMER, David M.; INGLE, Phillip B. and MORGAN, Stephanie H. Integrated Volt/VAR Control on Rural Distribution Systems. REPC (2011), pp 1-9.

[10] JAUCH, E. Tom. Implementing "Smart Grid" Integrated Distribution Volt/var/kW Management. Transmission and Distribution Conference and Exposition (2010), pp 1-9.

[11] ALBU, Mihaela M. et al. Monitoring voltage and frequency in smart distribution grids. A case study on data compression and accessibility. Power and Energy Society General Meeting (2010), pp. 1-6.

[12] PEREIRA, P. R. S. et al. Optimization of voltage regulators settings and transformer tap zones in distribution systems with great load variation using the smart grids initiatives. CIRED (2011), pp. 1-6 .

[13] The MathWorks,Inc.;Fuzzy Logic Toolbox User's Guide. http://www.mathworks.com/help/toolbox/fuzzy/fp754.html

[14] Jang, J.S.R.; Chuen-Tsai Sun. Neuro-Fuzzy modeling and control. Proceedings of the IEEE, Vol. 83, 2002, pp. 378 - 406.

[15] Pedrycz, W.; GOMIDE, Fernando. Fuzzy Systems Engineering: Toward Human-Centric Computing. 1. ed. Indianapolis: John Wiley \& Sons, 2007. Vol. 1. pp 1-544. 